\title{
Serial cardiac function tests in myocarditis
}

\author{
Candace L. Miklozek, Elizabeth M. Kingsley, Clyde S. Crumpaker, John F. \\ Modlin, Henry D. Royal, Patricia C. Come, Roger Mark and Walter H. Abelmann
}

\begin{abstract}
Charles A. Dana Research Institute and the Harvard-Thorndike Laboratory of Beth Israel Hospital, and the Department of Medicine (Cardiovascular Division), Beth Israel Hospital and Harvard Medical School, Boston, Massachusetts, Department of Medicine, The Memorial Hospital and Brown University, Pawtucket, Rhode Island, USA
\end{abstract}

\begin{abstract}
Summary: Sixteen patients (mean age 27 years, range 16 to 39 years) with the diagnosis of myopericarditis established by strict clinical criteria were evaluated following recovery 0.7 to 4.0 years (mean 2.7 years) later. Evidence of an acute viral infection was present in $44 \%$. During the acute illness, the major clinical manifestations consisted of pericarditis in 10 patients, acute myocardial infarction in 5 , right ventricular dysfunction in 5, bundle branch or hemiblock in 4, ventricular arrhythmias in 3 , congestive heart failure in 3 and cardiogenic shock and inappropriate sinus tachycardia in one patient each. Holter monitoring, echophonocardiography and radionuclide ventriculography results were abnormal in 57, 67 and $64 \%$ of patients respectively. At follow-up, these tests were abnormal in 67,7 and $73 \%$. Focal wall motion abnormalities were present in five. Seventy-five percent of patients had one or more abnormal tests at last follow-up. Although 8 patients had improved by a scoring system, 5 patients had an increase in the number of abnormal tests, including one who died. These findings indicate that persistent abnormalities following recovery from myopericarditis are not rare and support the hypothesis that the syndrome of dilated cardiomyopathy may be a sequel of myopericarditis.
\end{abstract}

\section{Introduction}

The syndrome of dilated cardiomyopathy has been suggested by many to be a late complication of acute viral myocarditis (Smith, 1970; Sainani et al., 1975; Bengtsson \& Lamberger, 1966). Advances in the noninvasive technology used to evaluate cardiac function have made study of this postulate feasible.

In 1979, we undertook a 5 year clinical prospective study based on this hypothesis. Our goal was to determine if cardiac function deteriorated over time following clinical recovery from myopericarditis. We identified 16 patients using strict criteria for the diagnosis of myopericarditis and studied them at periodic follow-up intervals with a wide array of noninvasive tests of cardiac function. We have already presented earlier follow-up results from these patients (Miklozek et al., 1984). We now present the latest results.

\section{Materials and methods}

\section{Criteria for the diagnosis of myopericarditis}

Myopericarditis was diagnosed if the patient de-

Correspondence: C.L. Miklozek, M.D., The Memorial Hospital, Pawtucket, RI 02860, USA. veloped new cardiac abnormalities during symptoms of an acute viral infection and had no known cardiac disease, cardiac risk factors, history of alcohol abuse, and did not have endocarditis or another systemic disease. In order to be eligible, patients had to be less than 55 years of age.

\section{Acute illness}

A carèful history and physical examination were obtained in each patient. Non-invasive studies consisted of standard 12 lead electrocardiograms, M-mode echocardiograms, phonocardiograms, Holter monitoring for 24 hours and radionuclide ventriculograms. A Holter monitor was considered abnormal if one of the following was present: (1) intraventricular conduction disturbance, (2) A-V block, (3) multiform or frequent premature ventricular or atrial beats, or (4) supraventricular tachycardia. The echocardiographic left ventricular ejection fraction was calculated from the formula of Teichholz et al. (1976); an ejection fraction less than $55 \%$ was considered abnormal. The mean velocity of circumferential fibre shortening (mVcf) was measured according to Cooper et al. (1972); a mVcf less than $0.83 \mathrm{circ} / \mathrm{s}$ was abnormal. The PEP/LVET ratio was calculated from systolic time intervals obtained from the phonocardiograms as

(C) The Fellowship of Postgraduate Medicine, 1986 
described by Tavel (1979); a PEP/LVET ratio greater than 0.420 was considered abnormal. Radionuclide ventriculograms were performed in most patients by intravenous injection of pertechnetate $99 \mathrm{~m}$ labelled red blood cells; left ventricular ejection fraction was calculated by the count method of Parker et al. (1977).

\section{Viral studies}

Urine, stool, and throat specimens from each patient were inoculated into continuous cell line cultures maintained in the Virology Laboratory at Beth Israel Hospital. Sera were collected during the acute illness and at least 2 weeks later for determination of microneutralization antibodies. In some patients, sera were sent to the State Board of Health and to Dr John V. Sullivan at the University of Massachusetts for measurement of antibodies to cytomegalovirus and Epstein-Barr virus, respectively.

\section{Follow-up studies}

Patients were seen by either CLM or WHA or the primary care physician at various intervals in time following clinical recovery. Whenever possible, electrocardiograms, M-mode echophonocardiograms, radionuclide ventriculograms, 24 hour ambulatory Holter monitoring and symptom limited exercise tests were performed. Exercise tests were performed in conjunction with radionuclide ventriculography using a bicycle ergometer in most patients. Endpoints for the exercise test consisted of (1) onset of cardiac symptoms, (2) significant depression of the S-T segments and/or inversion of the T waves, (3) dysrhythmias, (4) attainment of $85 \%$ of the age predicted maximal heart rate, or (5) hypotension.

\section{Results}

Sixteen patients with the clinical diagnosis of acute myopericarditis and with available follow-up studies were enrolled from 1979 to 1981 . The duration of follow-up ranged from 0.7 to 4.0 years with a mean of 2.7 years. Twelve were males. The mean age was 27 years and ranged from 16 to 39 years. All patients survived the acute illness. One patient died 8.3 months later. There were no other deaths.

\section{Acute illness}

Seven patients $(\mathbf{4 4 \% )}$ ) had evidence of an acute viral infection by culture or antibody titre. Echovirus 11 was isolated from 5 patients. Another, although culture negative, had stable but elevated titres $(1: 40)$ to echovirus 11. In one of these patients, Coxsackievirus B-3 was also isolated during a subsequent episode of myopericarditis. A seventh patient had both a fourfold rise in titre to cytomegalovirus and reactivation of an Epstein-Barr virus infection.

At the time of diagnosis, the following major cardiac abnormalities were present with overlap in the individual patient of myocardial and pericardial manifestations. Ten patients had pericarditis based on either history, electrocardiogram, presence of a pericardial rub, or effusion by echocardiography. Five presented with evidence of an acute myocardial infarction. Five had clinical right ventricular dysfunction with elevated venous pressure and a right ventricular heave. A bundle branch or hemiblock was present in four patients, while ventricular arrhythmias occurred in three patients. One patient had an inappropriate sinus tachycardia. Congestive heart failure developed in three patients, one of whom had cardiogenic shock.

Abnormalities were commonly detected by all methods used. Cardiac symptoms were elicited from $88 \%(14 / 16)$, and the examination was abnormal in $94 \%(15 / 16)$. Electrocardiograms, Holter monitoring, echophonocardiograms, and radionuclide ventriculograms were abnormal in $88 \%(14 / 16), 57 \%(8 /$ $14), 67 \%(10 / 15)$ and $64 \%(9 / 14)$, respectively. A broader definition of abnormalities by Holter monitor was used in this report and explains the larger number of abnormals when compared to our initial report (Miklozek et al., 1984). Focal wall motion abnormalities by radionuclide ventriculograms were present in 3 patients.

\section{Follow-up}

At follow-up, 44\% (7/16) still had cardiac symptoms, while the physical examination was abnormal in $63 \%$ (10/16). Electrocardiograms, Holter monitoring, echophonocardiograms, radionuclide ventriculograms, and exercise tests were abnormal in $60 \%(9 / 15)$, $67 \%(6 / 9), 7 \%(1 / 14), 73 \%(11 / 15)$, and $8 \%(1 / 13)$, respectively. Regional wall motion abnormalities were present in five by radionuclide ventriculography. The ejection fraction by echocardiography had increased from $58 \pm 2.7 \%$ (s.e.m.) to $69 \pm 1.8 \%$ (s.e.m.) $(P<0.005)$, while mean Vcf increased from $1.18 \pm 0.9$ circ/s (s.e.m.) to $1.31 \pm 0.5 \mathrm{circ} / \mathrm{s}$ (s.e.m.) (not significant) in 13 of the group. The PEP/LVET ratio calculated from the phonocardiogram decreased from $0.400 \pm 0.2$ to $0.310 \pm 0.05$ (s.e.m.) (not significant) in 12 of the group. Ejection fraction by radionuclide ventriculography decreased from $62 \pm 3.8 \%$ (s.e.m.) to $55 \pm 3.9 \%$ (s.e.m.) (not significant) in 13 of the group. Only 10 of these were also included in the echocardiographic group above.

Since all tests could not be performed in all patients, we attempted to compare the patients by the following method. A scoring system was devised in which each patient received one point for each abnormal category. 
The number of points was then summed and divided by the total number of categories and expressed as a percentage. The categories consisted of (1) symptoms of myocardial dysfunction, (2) ventricular enlargement by physical examination, and (3) conduction disturbances or dysrhythmias by electrocardiogram or (4) by Holter monitoring, (5) echophonocardiogram and (6) resting radionuclide ventriculograms. The maximum score possible was 6 points per visit, or $100 \%$. By this system, 8 patients improved, 3 patients showed no change, and 5 patients deteriorated.

\section{Discussion}

We have followed 16 patients with myopericarditis for a mean period of 2.7 years following clinical recovery using a wide variety of non-invasive tests of cardiac function. The diagnosis of myopericarditis was based on strict clinical criteria. Patients were less than 55 years of age, did not have known prior cardiac disease or alcoholism, and had new cardiac abnormalities during symptoms of an acute viral infection. Evidence of a viral infection was found in $44 \%$. The large prevalence of cardiac symptoms and abnormalities by examination and by electrocardiograms is explained by the strict criteria used in identifying patients with myopericarditis. Holter monitoring, echophonocardiograms, and radionuclide ventriculograms identified abnormalities in 57,67 , and $64 \%$, respectively.

\section{References}

BENGTSSON, E. \& LAMBERGER, B. (1966). Five-year followup study of cases suggestive of acute myocarditis. American Heart Journal, 72, 751.

BERGSTROM, K., ERICKSON, V., NORDBRING, F., NORDGREN, F., NORDGREN, B. \& BARRON, A. (1970). Acute non-rheumatic myopericarditis: a follow-up study. Scandinavian Journal of Infectious Disease, $2,7$.

COOPER, R.H., O'ROURKE, R.A., KARLINER, J.S., PETERSON, K.L. \& LEOPOLD, G.R. (1972). Comparison of ultrasound and cineangiographic measurements of the mean rate of circumferential fiber shortening in man. Circulation, 46, 914.

MIKLOZEK, C.L., COME, P.C., ROYAL, H.D., CRUMPACKER, C.S. \& ABELMANN, W.H. (1984). In Viral Heart Disease-A Precursor of Congestive Cardiomyopathy; Viral Heart Disease, Bolte H.-D. (ed). p. 95. Springer-Verlag: Berlin, Heidelberg, New York, Tokyo.

PARKER, J.A., UREN, R.F., JONES, A.G., MADDOX, D.E.,
During this stage, global and regional dysfunction of either or both ventricles was not unusual.

Following apparent recovery, cardiac symptoms and abnormalities by examination and non-invasive testing continued to be common. Seventy-five percent of patients had one or more abnormal tests of cardiac function. In most, these findings were subclinical although one patient died. By our scoring system, 8 patients had improved, but 5 patients showed an increase in the number of abnormal tests.

Our findings indicate that persistent cardiac dysfunction after recovery from acute myopericarditis is not unusual. These findings are consistent with the observations of others. Bengtsson \& Lamberger (1966) noted persistent electrocardiographic abnormalities following recovery from presumed myocarditis, as did Bergstrom et al. (1970). Residual electrocardiographic findings were observed in four and chronic heart failure in three of 19 patients up to 10 weeks after acute heart disease due to Coxsackievirus B by Sainani et al. (1975); five of those with abnormal tracings had cardiomegaly. Smith (1970) described 6 patients with abnormal electrocardiograms for 6 months to 6 years and 3 with residual cardiomegaly by chest X-ray following acute Coxsackievirus B heart disease. The demonstration of persistent abnormalities by non-invasive testing of cardiac function following clinical recovery supports the postulate that one cause of the syndrome of dilated cardiomyopathy may be acute viral myopericarditis.
ZIMMERMAN, R.E., NEILL, J.M. \& HOLMAN, B.L. (1977). Radionuclide left ventriculography with the slant hole collimator. Journal of Nuclear Medicine, 18, 848.

SAINANI, G.S., DEKATE, M.P. \& RAO, C.P. (1975). Heart disease caused by Coxsackie virus B infection. British Heart Journal, 37, 819.

SMITH, W.G. (1970). Coxsackie B myopericarditis in adults. American Heart Journal, 80, 34.

TAVEL, M.E. (1979). In The Carotid Pulse Tracing: Its Clinical Application; Clinical Phonocardiography and External Pulse Recording, Tavel, M.E. (ed). p. 187. Year Book Medical Publishers: Chicago, London.

TEICHHOLZ, L.E., KREVLEN, T.H., HERMAN, M.V. \& GORLIN, R. (1976). Problems in echocardiographic volume determinations: echocardiographic angiographic correlations in the presence or absence of asynergy. American Journal of Cardiology, 37, 7. 